\title{
THE POSITIVE IMPACT OF THE HOME/FAMILY ENVIRONMENT ON ARABIC LANGUAGE MAINTENANCE AMONG THE ARABIC SPEAKERS IN THE REGIONAL QUEENSLAND CITY OF TOOWOOMBA, AUSTRALIA
}

\author{
Dr.Mostefa Abdelhadi \\ University of Southern Queensland \\ Email: mostefaabdelhadi@yahoo.com.au
}

\begin{abstract}
This paper endeavours to scrutinize the role of the home/family domain as a key factor that may contribute to the maintenance of the Arabic language within the Arabic-speaking community in the regional Queensland city of Toowoomba, Australia. A qualitative approach was utilized in order to explore the language maintenance phenomenon by engaging in the everyday life of the Arabic speakers. Data was collected through participant observations and in-depth semi-structured interviews with 20 adults who were selected using a mixed purposeful sampling strategy. The findings of this study suggest that the home/family domain has a positive impact on Arabic language maintenance. The conclusions of this study are envisaged to enrich the knowledge and theories of language maintenance, as well as redesigning the multilingualism and multiculturalism structure of the Australian society.
\end{abstract}

Keywords: Language Maintenance, Community Language, Home/Family Domain, Arabic Language.

\section{Introduction}

The maintenance of community languages has always been a challenging field for investigation (Jamai, 2008). The majority of these languages live under the cultural power of the host country language. Therefore, it has never been an easy task for immigrants and their children to maintain their community languages, especially under the linguistic and cultural pressures of the English language (Rubino, 2010). Most community languages lose ground to English and adopt English in several domains in everyday life and this is a sign of language shift (Baker, 2011).

Research has found that language shift is more noticeable among immigrant children than their first generation parents (Clyne; 2003, 2005). For example, Hatoss, Starks and Janse van Rensburg (2011), in their research about the maintenance of Afrikaans among the South African community in South East Queensland, found that the reduction in the language use among immigrants was visible among those who immigrated at an early age and also the second generation children who were born overseas. Hence, second generation children tend to adopt the host country language at the expense of their parents' native language due to the absence of intergenerational maintenance and a transmission of this language at home.

It is argued by Holmes (2013) that language shift is predictable in monolingual countries such as Australia, New Zealand, England and the USA, where English is a dominant and prestigious language. In Australia, statistics demonstrate that only a few languages have withstood the cultural strength and high status of English language (ABS, 2011). Table 1 depicts the top 10 languages maintained at home in Australia in 2011. 
Table 1: Top 10 Languages Spoken in Australia at Home (a) (b)

\begin{tabular}{lcclc}
\hline $\begin{array}{c}\text { Language } \\
\text { spoken at } \\
\text { home in } \\
\text { Australia }\end{array}$ & $\begin{array}{c}\text { Persons } \\
\text { 'ooo' } \\
\text { (Speakers } \\
\text { in } \\
\text { thousands) }\end{array}$ & $\begin{array}{c}\text { Proportion } \\
\text { of total } \\
\text { population, } \\
\text { \% }\end{array}$ & $\begin{array}{l}\text { The } \\
\text { proportion } \\
\text { who spoke } \\
\text { English } \\
\text { very well } \\
\text { \% }\end{array}$ & $\begin{array}{c}\text { Proportion } \\
\text { born in } \\
\text { Australia \% }\end{array}$ \\
\hline English only & 15394.7 & 80.7 & N/A & \\
Mandarin & 319.5 & 1.7 & 37.5 & 83.8 \\
Italian & 295.0 & 1.5 & 62.1 & 43.2 \\
Arabic & 287.4 & 1.4 & 61.9 & 38.5 \\
Cantonese & 254.7 & 1.3 & 46.4 & 19.9 \\
Greek & 243.3 & 1.3 & 65.0 & 54.1 \\
Vietnamese & 219.8 & 1.2 & 39.5 & 27.9 \\
Spanish & 111.4 & 0.6 & 62.1 & 21.9 \\
Hindi & 104.9 & 0.5 & 80.2 & 9.8 \\
Tagalog & 79.0 & 0.4 & 66.9 & 5.9
\end{tabular}

Source: Australian Bureau of Statistics (ABS, 2011)

As shown in Table 1, a number of languages have been maintained by their speakers and the Arabic language is one of the most spoken languages at home in Australia. Only 19.3\% of the Australian population can resist the linguistic and cultural power of the English language. It is noticeable from the statistics that languages such as Arabic, Vietnamese, Cantonese, Greek, Mandarin, and Italian have been stable and well-maintained for the last three decades. However, some European languages such as Dutch, German, Austrian, French, Maltese and Hungarian are shifting with highs rate of adoption of English as the only means of communication (Hatoss, 2013).

It should be noted, however, that the maintenance of community languages remains a major concern for linguists, educators, language activists and for immigrant families, who need to support and maintain these languages for the next generation. Fishman (1996) raised a very serious and important question: "What are you going to do with your mother tongue?" (p. 80). This is a very decisive question because it determines the fate of the language either to be maintained and preserved for the second generation or to be lost.

The purpose of this study is to explore language maintenance efforts, experiences and challenges confronting the Arabic-speaking community in the regional city of Toowoomba, Australia, and to identify themajorrole of home/family domain in the maintenance of Arabic language within the Arabic-speaking community in Toowoomba, Australia.

\section{Literature Review}

Community languages can be maintained through several domains based on the speakers' choices and preferences. These language domains include home/family, friends, neighbours, community, religion, education, and the media, as suggested by Fishman (1991). Baker (2011) points out that the regular use of community languages amongst family, friends, neighbours and the local community is referred to as language targets. The use of community languages in the home domain is recorded every five years by the Australian Census (ABS, 2011). However, some of these languages have been maintained in several domains other than the home. In this paper, the focus will be on the role of the home/family as an important factor for Arabic language maintenance. 


\subsection{The Role of the Home/Family in the Maintenance of Arabic Language}

Research has shown that maintenance of the community language is based on the role of the family at home (Clyne, 2003, 2005; Pauwels, 2005). The home is the only domain where the family has close control of the children in terms of communication and transmission of the community language. Children get exposed to the majority language of the host country outside the home domain in places such as schools and playgrounds. The home/family environment is a motivating factor in the promotion of successful intergenerational maintenance of the community language. As indicated by Clyne (2003, 2005), language is not going to survive another generation unless it is transmitted in the home within the family.

Similarly, Fishman (1991) has proposed the model " Graded International Disruption Scale (GIDS)" which is made up of eight stages of reversing language shift. He argued that stage six is very important stage of the model GIDS as it involves to the major role of the home/family as the basis of mother -tongue transmission. According to Fishman, the intergenerational language transmission starts at stage six which includes the family/home. The parents should pass on their community language continuously and constantly to the forthcominggenerations in order to foster the acquisition and maintenance of that language.

In the same context, Gomaa (2011) investigated the use of Arabic among five Egyptian families living in Durham, UK. His interview results revealed thatmost of these families implemented a strict home policy to practise Arabic with their children. Participantsinsisted that theyaddress their children in Arabicat home as they have a full access to the dominant language at school with their peers. The results also indicated that some English words are slightly used among the family members which reflected their desires to bring up their children bilingually as interpreted by the author. According to Gomaa, the home domain is the best factor to maintain Arabic as a tool for interactions and communication among the family members.

Pauwels's (2005) research about language dynamics in families reported that children who were exposed to a community language at home, usually became more proficient in maintaining good receptive skills even if their productive skills were imperfect. According to the 2011 Census, 19.3\% of the Australian population used a language other than English at home (ABS, 2011). The Arabic language was among the most commonly spoken languages other than English at home in Australia for the period of 1991 to 2011 (ABS, 2011).

It is concluded that the dynamic use of the minority language in the home domain is a sign that the language maintenance is inevitable. Fishman (1991) argues that the role of some other language maintenance domains such as school and community efforts is mainly symbolic in the absence of the home-family reliable role in the integenertional language maintenance and transmission.Conversely, Holmes (2013) and Lee (2013) claimed that the limited use of the minority language in private domains such as the home is an indicator of the shift to the majority language. Also, (Clyne 2003) claimed that the language used at home may be affected by external factors such as mixed marriages, the birth of new children, entering the workforce, and children's departure from the parental home.

\section{Methodology}

\subsection{Participants}

In this qualitative study, the sample size was determined by the concept of saturation. The researcher was looking for the factors that may contribute to the maintenance of the Arabic language within the Arabic speaking community in the regional city of Toowoomba. The sample included 20 participants who were drawn purposefully from the community membership list at the Mosque.

A mixed purposeful sampling technique was used for recruiting 20 Arabic speakers from the mosque in the regional city of Toowoomba, Australia to participate in this study. Firstly, the 
researcher conducted a purposive sampling technique at first in order to select 12 adult male participants from the membership list at the mosque. This list includes the population of about 1000 male adult individuals who are members of the mosque by paying annual membership fees. The Arabic speakers represent a majority of people at the Mosque.

The selection criteria for participation were: (1) adult first generation Arabic native speaker, (2) Arab in ethnicity, (3) married with at least one child. Second, eight female participants were recruited by a female research assistant using a snowballing technique. In this technique, each participant who agreed voluntarily to participate in this study was asked to identify other participants who met the selection criteria mentioned above and were willing to participate (Johnson \& Christensen, 2012). The snowballing technique was utilized due to the difficulty in finding female participants since they do not regularly come to the mosque. Additionally, there were other constraints such as religious and cultural concerns among Arabic speakers. In view of that, the researcher was obliged to appoint a female research assistant to recruit, interview and observe female participants.

With respect to their age, the majority are in their 30s; there are only four in their 40 s and two in their late 20s. All the participants came to Australia in the last decade between 2006 and 2013. Withregards to education, 90\% of the participants were still students during the time the research was conducted. Among them, 35\% were undertaking Ph.D. studies, $35 \%$ a Master's Degree, 25\% a Bachelor of Arts Degree, and 5\% had a High School Certificate. A larger proportion came to study and subsequently preferred to settle down and live in Australia. However, there were only two male participants who were married to non-Arabicspeaking spouses. Their wives came from English-speaking countries: Australia and New Zealand.

\subsection{Data Collection Strategies}

Firstly, in order to answer the research questions, data were first gathered using in-depth, semi-structured interviews with the 20 Arabic speakers who met the sample selection criteria discussed in the "Participants" section. Secondly, in order to learn more about the participants' perspectives and experience, data were collected through observation in which the researcher observes and take field notes from the participants' interaction in order to form a better understanding of the central phenomenon.

\subsection{Ethical Considerations}

Approval for this research was gained from the Human Research Ethics Committee (HREC) at the University of Southern Queensland, Australia. All ethical concerns about all aspects of this research were clearly explained to the participants verbally and it was also included in the participant information sheet as well as in the consent form. Participants in this study were informed that their contribution was entirely voluntary and they had the full right to withdraw at any stage during the study without any consequences. Participants were informed that their identity would be protected by providing a pseudonym rather than their actual names.

\subsection{Data Analysis Procedures}

In the current study, the researcher adopted the same steps for analysing the data that are outlined in Creswell's (2014) plan of analysis. This plan involves going through several steps: (1) organizing and preparing data for analysis, (2) reading through all the gathered information in order to acquire a general sense of it, (3) coding the data by detecting text segments and giving a code label to them, (4) representing the data in tables or charts to convey information about each participant, and (5) making an interpretation of the data and comparing the findings with information found in literature (Creswell, 2014).The researcher found this plan very comprehensive and an easy way of dealing with the big amount of raw data gathered. A thematic analysis was utilized in this study, which involved going through all of the following steps: organising, transcribing and coding the data, to extract themes and sub-themes which would represent the findings of this study. Figure 1 is a summary of qualitative data analysis plan which refers to these steps: 


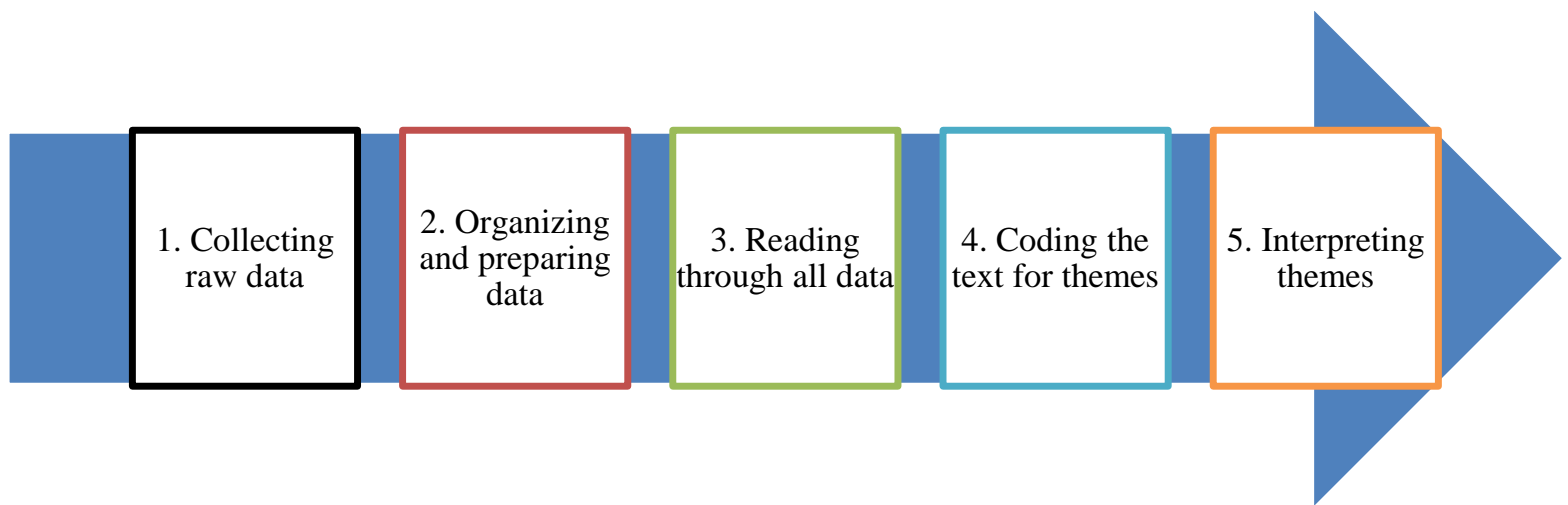

Figure 1: Qualitative Data Analysis Plan, Adapted from Creswell (2014)

\section{Findings}

This section describes the qualitative results that were uncovered through the use of in-depth semi-structured interviews and participant observations. The findings of this study are presented in two main sections: 1) general description of the sample, 2) description of the themes and sub-themes.

\subsection{General Description of the Sample}

The sample includes a total of 20 participants, 12 males and 8 females. This study did not intend to make a distinction or a comparison between male and female participants since there was no balanced sample, but rather to get a holistic understanding of the Arabic language maintenance from both genders' views. Participants in this study came from different Arab countries, including the Middle East and North Africa. Seven were Libyan, six were Iraqi, two were Moroccan, two were Omani, one was Saudi, one was Kuwaiti, and one participant was Emirati. All participants were bilingual speakers of Arabic and English, except for two participants who were multilingual. All the participants in this study were native speakers of Arabic, and Arab in ethnicity.

\subsection{Description of the Themes and Sub-themes}

The analysis of transcripts of both interviews and observations led to the emergence of several themes and sub-themes which contribute to the maintenance of Arabic among the Arabic-speaking community in the regional city of Toowoomba. In this section, the focus is on one theme which refers to the role of the home/family in the maintenance of Arabic language.

\subsubsection{The Role of Family/Home in the Maintenance of the Arabic Language}

This theme is found to be one of the core factors that support the maintenance of Arabic language within the Arabic speaking community in the regional city of Toowoomba.In response to the question: What languages do you speak at home with your children?, data analysis of the transcripts revealed that the home was the best place for intergenerational language maintenance and transmission of Arabic among the Arabic speakers living in Toowoomba. The role of the family at home played a significant role in Arabic maintenance. According to all participants, the Arabic language should be maintained at home within the family to pass it on to the second generation children. Table 2Table illustrates language maintenance in the home/family domain. 
Table 2: Language maintenance in the home/family domain

\begin{tabular}{|l|lc|lc|ll|}
\hline Participants & \multicolumn{2}{|c|}{ Arabic only } & \multicolumn{2}{|l|}{ English only } & \multicolumn{2}{l|}{$\begin{array}{l}\text { Mix (Arabic \& } \\
\text { English) }\end{array}$} \\
\hline Male $\mathrm{n}=12$ & 6 & $(30 \%)$ & $\mathrm{O}$ & $(0 \%)$ & 6 & $(30 \%)$ \\
\hline Female $\mathrm{n}=8$ & $\mathbf{1}$ & $(5 \%)$ & $\mathbf{1}$ & $(5 \%)$ & 6 & $(30 \%)$ \\
\hline
\end{tabular}

As Table 2Table indicates, six male participants reported that they spoke only Arabic at home. There was only one female member who spoke Arabic with her children at home because she was the only housewife who stayed at home all the time looking after her children. Also, the data analysis showed that there was one female Arabic speaker who reported that she spoke only English at home. There was a balance in number between male and female participants who tended to speak both Arabic and English with their children at home according to the participants' responses. In general, six male and six female participants spoke a mix of Arabic and English at home, but as they reported, Arabic was the dominant language within the family. English was usually used to help children with their homework.

\subsection{A-Speaking Arabic Only}

The male participants expressed their views about the use of Arabic language only at home. They said that their children were exposed to English everywhere outside the home environment, especially when they went to school through interactions with school peers. For this reason, they considered the home as the only place where children could learn Arabic. The following excerpts from the male participants reported their daily use of Arabic within the family:

To be honest, I speak Arabic at home. I need to, I need to give my kids the Arabic language because they are studying in the school English, the street is English, everywhere outside of the house is English. ... So I have, I must talk the Arabic language at home to teach my kids. (S3M)

Arabic definitely. We can't say 100\%, 99\% we speak Arabic, and because my wife, you know, I would love to practice this language in front of my child from the beginning, so he knows that we speak Arabic, and he should learn Arabic and so on. (S8M)

With my children, I try always to speak with my children Arabic because I want them to learn Arabic, because they are learning English at school, they can go and have friends speaking English, they can speak all time English, but if in this age, they are young and small, if you do not give him time to speak Arabic when he grow up, they will be lost, you cannot get Arabic, it is hard. (S4M)

All the comments made above by the Arabic-speaking fathers referred to their commitment to speaking Arabic with their children at home to help them acquire the language quickly. It seems clear from the data analysis that male participants are more likely to maintain their Arabic at home than female participants.

Another male participant reported that the Arabic language is the only language spoken at home with his family because his wife did not speak English. He said:

Yeah, yeah, I never speak with them in English because my wife, she does not speak English and, uh, also my kids, although you know the eldest son [Name] he is going to school, he is studying English, but I never speak English to him because I feel he will just acquire English at school, and just I speak at home I speak with him in Arabic. (S12M)

The statement above confirms the theories in the literature about the benefits of intermarriage within language communities. This participant was a bilingual speaker who found himself speaking only his language with his monolingual Arabic-speaking wife. Moreover, he chose to speak Arabic only with his children, despite their familiarity with English. 
It was unexpected that there was only one female out of eight who mentioned that she spoke Arabic at home with her family. Usually, intergenerational maintenance and transmission of the community language is based on the role of women at home as they do not go out much in the Middle Eastern Muslim culture. She said:

I speak Arabic, some words of English, but all the time in Arabic. (S17F)

\subsection{B-Speaking English Only}

Results from the interviews revealed that there was only one female participant out of eight who reported that she spoke just English with her daughter at home. She said:

When I talk with my daughter we speak in English I can see that her first language is English. Even how her chin moves in English letters rather than Arabic letters. (S2OF)

As the statement above indicates, there was only one female participant who stated that English is the first language of communication within her family. That is why there was no equal views between males and females. Also, this study is not focusing on the comparison between males and females rather to explore their experiences and views about the maintenance of Arabic at home.

\subsection{C-Speaking Arabic and English}

About 12 participants mentioned that they spoke both Arabic and English, but their focus was always on the Arabic language as their children could learn English outside the home surroundings. There were an equal number of Arabic speakers who spoke both Arabic and English, six male and six female participants. The following are statements supporting the male participants' opinions about their choice of using both languages:

It is a kind of mix, my kids, they speak, my older son and daughter they speak to each other in English, they speak with mix mixed Arabic and English, they speak with their mother and little brother in Arabic. (S1M)

Totally in Arabic, but I am trying to teach my kids English because my daughter, she will go to school next year. So, I enrolled her in Childcare four months; she learns some from, because my stay in Australia is only for four years, for studying and go back to my country. So, my priority is to keep Arabic as mother tongue because as you know Arabic is very important for us because Qur'an is revealed in Arabic, and it is important to know Arabic well, to understand the religion. (S7M)

Both [Arabic and English], the focus is on Arabic. I want my children to be a native Arabic speaker. It is hard to be native Arabic speakers while they live in an English native country, but I am trying my best me and my wife to teach them to be native Arabic speakers. Yes, because I believe that from the childhood if they did not learn the language, they will never improve this language. So, with the presence of the kids, many times I use Arabic. (S1OM)

Female participants' perspectives about the use of Arabic language at home are indicated below in their statements. They reported that they spoke both Arabic and English within their family environment.

Yeah, I speak Arabic and English yeah. Because I told you I am studying part-time ah, they go to childcare ah the whole week so you know they are still young, so they acquire the English, so quickly. So that is why I am trying to speak with them Arabic as well as English to them so they can balance both of them. But the most important one for me is Arabic because I am focusing on Arabic... because I know they will get so so good in English because all the communities, the TV is English, they got childcare English. (S13F)

Now, we speak Arabic and English. Ah, my kids always mixing the language, both languages in one sentence sometimes (laughter). (S14F) 
Mix because they are now at school. My eldest is in Grade 3, and now they mix languages when they speak to each other at home. I try to speak to them in Arabic now so that they do not forget the Arabic language. (S18F)

The analysis of the interview data revealed that home/family domain has a great impact on Arabic language maintenance and it is the starting point for learning and practising the parents' language. All participants commented on the role of home/family as a crucial factor for the maintenance and transmission of Arabic to their second generation children.

\section{Discussion}

The first observable limitation in this qualitative ethnographic inquiry is related to the generalization of the findings. The aim of this investigation was to explore the experiences and challenges of the Arabic-speaking community rather than to generalize to a larger population. The role of home/family has been found to be a keyfactor in the field of language maintenance, according to several linguists (Clyne, 2005; Fishman, 1991).

\subsection{The Role Home/Family Domain in the Maintenance of the Arabic Language}

Based on the majority of participants' statements, the home/family factor is the best strategy for the intergenerational transmission of Arabic. The majority of Arabic-speaking parents focused more on speaking Arabic at home within the family than English, in order to facilitate the intergenerational transmission of the language. This finding is supported by several researchers and advocates of minority languages (Clyne, 2005; Fishman, 1991; Gomaa, 2011; Hatoss, 2013; Pauwels, 2005). Pauwels (2005) reported that the family is an essential domain for the development of the community language. Also, Fishman's (1991, 2001) model indicates that the intergenerational transmission of the community language at home is needed for its maintenance. Stage six in Fishman's model is relevant to the maintenance of the Arabic language among the Arabic-speaking community in Toowoomba, amongst whom intergenerational use of Arabic in the home/family takes place on a regular basis in daily interactions because of its importance and value among this community.

More support for the importance of the home as a decisive factor in the maintenance and transmission of the community language to the second generation was found by Hatoss (2013) who stated: "Still, home language use is the most important factor in intergenerational language maintenance" (p. 73). Similarly, Gomaa (2011) noted that the home is the best factor for the maintenance and transmission of the Arabic language because it allows for its constant use in peoples' everyday lives.

This finding is consistent with Clyne and Kipp's (1999) viewswhichpointed out that "home has been the key element of language maintenance, if language is not maintained in the home domain, then it cannot be maintained elsewhere" (p. 47).

It is noticeable from reviewing the participants' transcripts that all the Arabic speakers were trying to bring up their children bilingually, but with a little more focus on Arabic. According to the participants, both Arabic and English were used within the family at home, but more concentration was given to the Arabic language. They wanted their children to reach the status of native Arabic speakers. They also believed that their children should be exposed to the language at a very early age to acquire the language.

According to the community under study the home/family domain was not just a central factor for the maintenance of the community language, but also for the promotion of bilingualism through the use of both Arabic and English. The use of both Arabic and English side by side in a multilingual and multicultural society will contribute to the maintenance of the Arabic language. This finding is in accordance with Fishman (1989), who found that the community language can be easily maintained when it is used side by side with the dominant language of the host country in a number of domains in the host country. It is also consistent 
with the results of Qawar (2014) who found that Arabs in Quebec used Arabic side by side with English and French in different domains and for different purposes.

\section{Conclusion}

The findings of this study suggest that home/family domain is quiteessential for the intergenerational language maintenance and transmission. The Arabic speakers in this study expressed their thoughts about their role and responsibility to transmit their language to their children at the home domain. They are all aware of the fact that language maintenance can occur only if the minority language is incorporated into the home/family domain. Although English is still used slightly at home, but the greater focus fall on Arabic.

Thus, the findings related to the maintenance of Arabic language in the regional city of Toowoomba are of value in enhancing the linguistic and cultural diversity in the Australian context. It may also contribute to the changing multilingual and multicultural structure of Australian society. Moreover, this study is intended to attract linguists' and educators' attention and to stimulate them to place more value on small isolated ethnolinguistic groups in their future research. At a practical level, this research may contribute to Australian multilingualism and multiculturalism by advocating the rights of small immigrant communities to be recognized. 


\section{References}

i. Australian Bureau of Statistics. (2011). Census of population and housing. Canberra.

ii. Baker, C. (2011). Foundations of bilingual education and bilingualism ( $5^{\text {th }}$. ed.). USA: Multilingual Matters.

iii. Clyne, M. (2003). Dynamics of language contact. Cambridge: Cambridge University Press.

iv. Clyne, M. (2005). Australia's language potential. Sydney: University of New South Wales Press.

v. Clyne, M., \&Kipp, S. (1999). Pluricentric languages in an immigrant context: Spanish, Arabic, and Chinese. New York: Mouton de Gruyter.

vi. Creswell, J.W. (2014). Research design. Qualitative, quantitative, and mixed methods (4 ${ }^{\text {th }}$. ed.).Thousand Oaks, CA: Sage.

vii. Fishman, J. A. (1989). Language and ethnicity in minority sociolinguistic perspective.Clevedon: Multilingual Matters.

viii. Fishman, J. A. (1991). Reversing language shift: Theoretical and empirical foundations of assistance to threatened languages.Clevedon: Multilingual Matters.

ix. Fishman, J. A. (1996). Maintaining languages: What works? What doesn't.In Gina Cantoni (Ed.), Stabilizing indigenous languages (pp. 186-198). Flagstaff, AZ: Northern Arizona University.

x. Fishman, J.A. (2001). Can threatened languages be saved?Clevedon: Multilingual Matters.

xi. Gomaa, Y. A. (2011). Language maintenance and transmission: The case of Egyptian Arabic in Durham, UK. International Journal of English Linguistics, 1(1), 46-53. Retrieved from http://www.ccsenet.org/journal/index.php/ijel/article/view/9295/7026

xii. Hatoss, A. (2013). Displacement, language maintenance and identity: Sudanese refugees in Australia. John Benjamins Publishing Company: Netherland. Retrieved from http://books.google.com.au/books?id=phFAgAAQBAJ\&printsec=frontcover\&source=gbs ge summary $\mathrm{r} \& \mathrm{cad}=\mathrm{O} \# \mathrm{v}=$ onepage\& $\mathrm{q} \& \mathrm{f}=$ false

xiii. Hatoss, A., Starks, D., \&Janse van Rensburg, H. (2011). Afrikaans language maintenance in Australia.Australian Review of Applied Linguistics, 34(1), 4-23. doi:10.2104/aral.v34i1.2114

xiv. Holmes, J. (2013). An introduction to sociolinguistics ( $4^{\text {th }}$ ed.). Pearson Education Limited: USA

xv. Jamai, A. (2008). Language use and maintenance among the Moroccan minority in Britain (Doctoral dissertation). Retrieved from http://usir.salford.ac.uk/2030/1/Language_Use_and_Maintenance_among_the_Moroccan _Minority_in_Britain-PhD.pdf

xvi. Johnson, B., \& Christensen, L. (2012). Educational research: Quantitative, qualitative, and mixed approaches (4th ed.). USA: SAGE Publications.

xvii. $\quad$ Lee, S. E. (2013). Spanish language maintenance and shift among the Chilean community in Auckland (Master's thesis, Auckland University of Technology). Retrieved from http://aut.researchgateway.ac.nz/bitstream/handle/10292/5555/LeeS.pdf?sequence=3

xviii. Pauwels, A. (2005). Maintaining the community language in Australia: Challenges and roles for families.International Journal of Bilingual Education and Bilingualism, 8(2-3), 124-131. doi:10.1080/13670050508668601

xix. Rubino, A. (2010). Multilingualism in Australia: Reflections on current and future research trends. Australian Review of Applied Linguistics, 33(2), 17.1-17.21. Retrieved fromhttp://www.nla.gov.au/openpublish/index.php/aral/article/viewFile/2050/2433 